\title{
Calculation and Use of Ion Activity
}

GEOLOGICAL SURVEY WATER-SUPPLY PAPER 1535-C 


\section{Calculation and Use}

\section{of Ion Activity}

By JOHN D. HEM

\section{GEOCHEMISTRY OF WATER}

GEOLOGICAL SURVEY WATER-SUPPLY PAPER 1535-C

Processes by which natural water acquires or relinquishes solutes, in relation to ionic activity

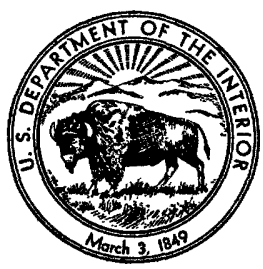


UNITED STATES DEPARTMENT OF THE INTERIOR

STEWART L. UDALL, Secretary

\author{
GEOLOGIGAL SURVEY
}

Thomas B. Nolan, Director 


\section{CONTENTS}

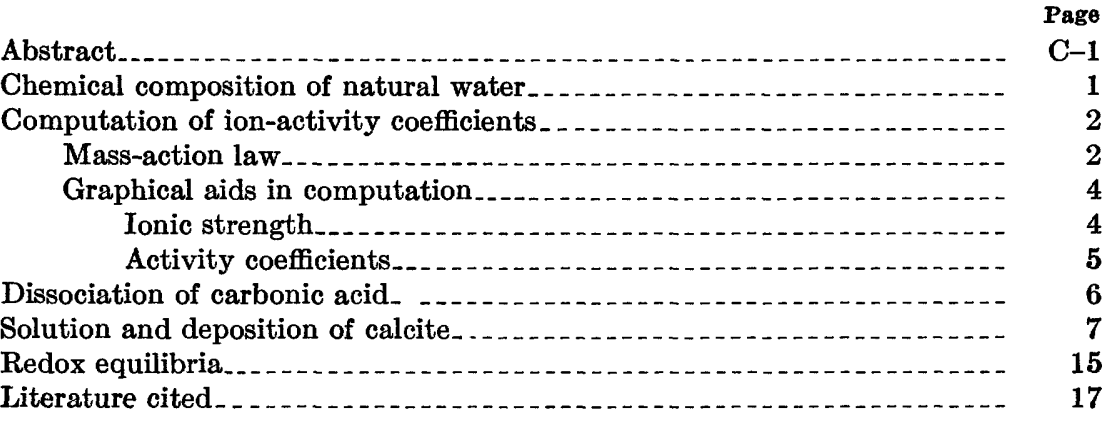

\section{ILLUSTRATIONS}

Page

Plate 1. Nomograph for computing ionic strength of natural water . - In pocket FIgure 1. Relation of activity coefficients of ions to ionic strength of solutions . . . .

2. Equilibrium $\mathrm{pH}$ for calcium and bicarbonate activities...... 15

\section{TABLES}

TABLE 1. Chemical analyses of ground water

3. Computation of equilibrium $\mathrm{pH}$ 



\title{
GEOCHEMISTRY OF WATER
}

\section{GALCULATION AND USE OF ION ACTIVITY}

\author{
By John D. Heм
}

ABSTRACT

A nomograph and a set of curves can be used to simplify the computation of activity from the measured concentration for constituents of natural water containing as much as 5,800 parts per million of dissolved solids. These devices are applied in mass-action computations of undissociated dissolved carbon dioxide, and computations of saturation status with respect to calcite in 16 samples of natural water whose dissolved solids content ranges from 91 to $4,170 \mathrm{ppm}$. When activity values are used to compute undissociated dissolved carbon dioxide, the value obtained is 5 to 25 percent less than when the computation is made without activity corrections. Computed saturation $\mathrm{pH}$ with respect to calcite is from 0.1 to 0.6 of a $\mathrm{pH}$ unit greater when activity corrections are made than when they are not.

Activity corrections are also used in computing redox potentials from dissolved iron and $\mathrm{pH}$ in natural water, but corrections are no more than 0.02 or 0.03 volt where ionic strength is 0.10 or less.

\section{CHEMICAL COMPOSITION OF NATURAL WATER}

Many of the processes by which natural water acquires dissolved impurities are reversible chemical reactions. The solutes come from the air, from minerals in the soil and rocks, and from vegetation or organic debris. The resulting solutions are normally dilute in the ordinary chemical sense. Opportunity for chemical equilibrium to be reached among solutes and minerals may occur, especially in ground water. Some reactions affecting natural-water composition are irreversible, and never reach equilibrium. If a reversible reaction proceeds slowly a water may retain metastable concentrations of some ions for a long time.

The processes by which natural water acquires or relinquishes solutes are complicated by many factors that seldom can be adequately evaluated. Thus, although techniques have been available for many years for the exact evaluation of the status of reversible reactions under laboratory conditions, the unknown, and perhaps unknowable factors in natural-water systems have discouraged the use of these evaluation techniques in natural-water chemistry. 
In this report several methods are given for simplifying the calculation of ion activity from standard water analyses. The calculation of activity is a first step in the quantitative application of the massaction law to natural-water chemistry. Examples of applications of the ion-activity data are cited, to show the magnitude of corrections introduced by the activity calculation, and to test, in a preliminary way, chemical equilibria in simple systems that can occur in ground water. These applications are made by using available generalpurpose chemical analyses.

The systems dealt with in natural-water chemistry are complex and the ordinary water analysis may not be an accurate representation of all the properties of the solution that should be known to apply the mass-action law and related chemical calculations. Discussions presented in this report on the equilibria among solids and solutes in ground-water systems do not imply ignorance of the complex factors, nor do they minimize such factors as unimportant. However, progress in the understanding of natural-water chemistry will be served by applying mass-law and related computations where some possibility of approximate equilibrium exists. The results may help evaluate the limitations that such computations have, as well as their potential usefulness, and show how that usefulness can be extended and improved.

\section{COMPUTATION OF ION-ACTIVITY COEFFICIENTS}

\section{MASS-ACTION LAW}

The mass-action law states that the rate of a chemical reaction is proportional to the active masses of the reacting substances. A reversible reaction ultimately reaches a state of equilibrium at which the rates of the forward and reverse reactions are equal. When the reaction

$$
a A+b B \rightleftharpoons c C+d D
$$

(where the reactants and products are represented by capital letters and the number of moles of each by the lowercase letters) is at equilibrium, the law can be stated

$$
\frac{[C]^{c}[D]^{d}}{[A]^{a}[\bar{B}]^{b}}=K
$$

where quantities in brackets represent active concentration (activity) of the reactants and products and $K$ is the equilibrium constant.

The activity of the dissolved ions in solutions of moderate dilution, such as potable natural water, is somewhat less than the concentration of the ions measured and reported in water analyses. To apply the mass-law computation accurately to such solutions, a factor should 
first be computed by which the reported concentration may be multiplied to yield active concentration or activity. This factor is the activity coefficient.

In most of the literature where mass-action calculations are applied to water chemistry, an activity coefficient of unity has been assumed. This assumption introduces no significant error at very low concentrations. The concentration range of potable water, however, may be above the level where unit activity coefficients can be accurately assumed. A limit of 500 or $800 \mathrm{ppm}$ is sometimes given as the maximum for reasonably accurate application of mass-action calculations without activity corrections.

Actually, for the concentration range of water that is dilute enough to be of practical value as a water supply, activity coefficients can be simply and accurately computed using an empirical statement of the Debye-Hückel law of interionic attraction which has been widely used in studying solutions of low to moderate concentrations. The activity coefficient $\gamma_{i}$ for an ion in such a solution is given by the expression

where

$$
\log \gamma_{i}=\frac{-A z_{i}{ }^{2} \sqrt{\mu}}{1+B a_{i} \sqrt{\mu}}
$$

$A$ is a constant relating to the solvent whose value for water at $25^{\circ} \mathrm{C}$ is 0.5085

$z_{i}$ is the charge of the ion

$B$ is a constant relating to the solvent, which for water at $25^{\circ} \mathrm{C}$ is $0.3281 \times 10^{8}$

$a_{t}$ is a constant relating to the effective diameter of the ion in solution

$\mu$ is the ionic strength of the solution

Values for $A, B$, and $a_{i}$ for different temperatures and common ions are given by Klotz (1950, p. 330-331) who selected them from published literature.

The ionic strength of a sample of natural water is computed from the expression

$$
\mu=\frac{\Sigma m_{i} z_{i}^{2}}{2}
$$

This equation may also be expressed

$$
\mu=\frac{m_{1} z_{1}^{2}}{2}+\frac{m_{2} z_{2}^{2}}{2} \ldots+\frac{m_{i} z_{i}^{2}}{2}
$$

where $\mu$ is the sum of a series of terms each of which is divided by 2 . In both equations, $m=$ molar concentration of a kind of ion in the 
solution, and $z$ is the charge on that ion. Most of the ionic strength of natural water will generally come from 2 to 6 ions.

\section{GRAPHICAL AIDS IN COMPUTATION}

\section{IONIC STRENGTH}

The computation of ionic strength, $\mu$, and the values of the activity coefficient, $\gamma$, for the ions reported in a large number of water analyses can be tedious. Plate 1 is a nomograph that shortens the process of calculating the ionic strength from water analyses in parts per million.

The right- and left-hand scales in plate 1 are identical and represent the value of $\frac{m_{i} z_{i}^{2}}{2}$ increments to the total ionic strength corresponding to the concentration of individual ions given on other scales in parts per million. To use the nomograph, a transparent straight edge is laid on it horizontally, intersecting the concentration value given in the analysis for a particular ion. That ion's contribution to the total ionic strength is read on either the right- or left-hand scales and recorded. The process is repeated for other ions present in amounts sufficient to affect the total ionic strength significantly, and the total for $\mu$ is then determined by adding the increments together. The nomograph gives results accurate to about 2 significant figures and covers the concentration ranges of the substances commonly found in natural water up to an ionic strength of about 0.10 .

A part per million of magnesium contributes more to the total ionic strength of the solution than an equal amount of any other cation given in plate 1 . Some cations commonly present in minor amounts such as $\mathrm{Al}^{+3}$ or $\mathrm{H}^{+}$, however, have greater effects on the ionic strength. Of the anions given in plate 1 , carbonate and fluoride are the most effective in increasing the ionic strength, but these anions rarely are present in major amounts. Sulfate is the most effective of the common anions.

The expression for computing activity coefficients is applicable up to an ionic strength of 0.1. A solution of magnesium sulfate with 3,100 ppm dissolved solids is near this value. However, when other ions predominate, a much greater amount of dissolved solids can give the same ionic strength. For water containing dissolved sodium chloride, for example, about $5,800 \mathrm{ppm}$ total dissolved solids gives a value of $\mu$ as 0.10 ; for water containing sodium bicarbonate, the total concentration would be $8,400 \mathrm{ppm}$. In computing or determining the total dissolved solids for such water, however, by conventional procedure, the bicarbonate would be reported in terms of equivalent amounts of carbonate, so the dissolved-solids value for this water would be given as $5,300 \mathrm{ppm}$. 


\section{ACTIVTTY COEFHICLENTS}

After the ionic strength, $\mu$, has been computed, figure 1 can be used to give the activity coefficient for each ion in the solution. Figure 1 was prepared from the mathematical expression for $\gamma$ (see p. C-3) using values for the constants given by Klotz. Similar graphs have been published by many authors.

A value for $\gamma$ greater than about 0.95 is close to unity, and it normally is not worth while to change measured goncentration to activity where the correction is so small. For water containing sodium chloride of ionic strength 0.002 (about $116 \mathrm{ppm}$ dissolved solids) or less, the $\gamma$ value for sodium and chloride is more than 0.95 . For water containing magnesium sulfate however, the $\gamma$ value for magnesium and sulfate will only be 0.95 if the ionic strength is below 0.0001 (dissolved-solids concentration less than $31 \mathrm{ppm}$ ).

For many purposes, an uncertainty in the final result greater than 5 percent could be tolerated. However, the activity coefficient for

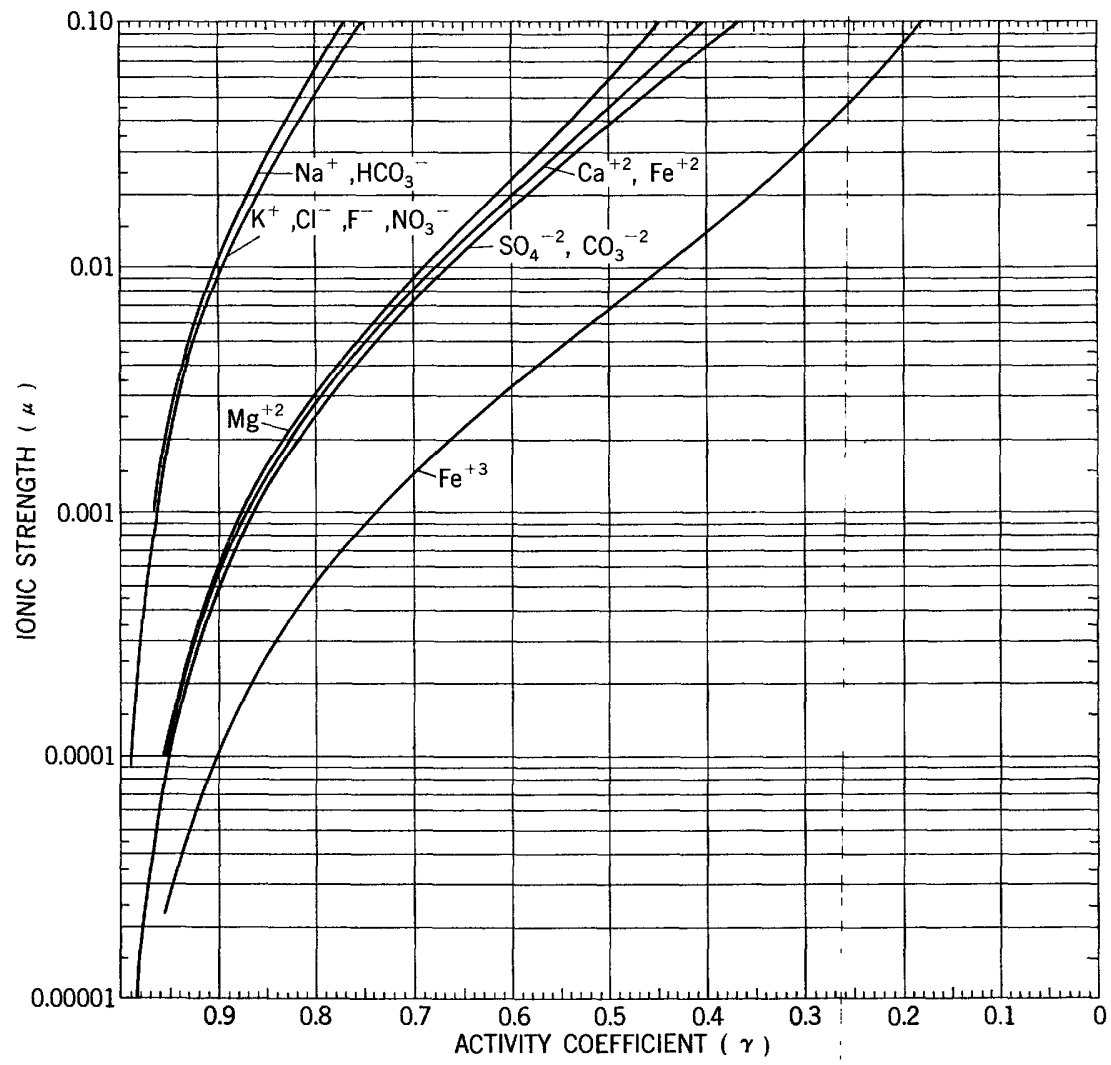

FIgURE 1.-Relation of activity coefficients for important ions in natural water to ionic strength of solutions. 
divalent ions in water of 0.01 ionic strength is shown by figure 1 to be from 0.65 to 0.70 . An ionic strength of 0.01 is equivalent to 300 to $500 \mathrm{ppm}$ dissolved solids, and is a common range for natural-water concentrations.

The following computations represent simple applications of the mass-action law to water analyses. The effect on final results of using or ignoring activity corrections will be indicated. In all the applications made in this report, the formation of complex ions in solution is not considered.

\section{DIssocration OF CARbonIC ACID}

The mass-action law provides a convenient approach to a study of the behavior of dissolved carbon dioxide present in natural water. Many reports have been published on this topic. Dissociation constants for carbonic acid, pH values, and titrated "alkalinity" (as this term is used in water analysis) provide a basis for computing the amount of carbon dioxide that may be in solution in an undissociated form (Moore, 1939). Activity corrections make this computation valid for higher dissolved-solids concentrations than the 500 to 800 ppm dissolved solids sometimes given as the top limit by some authors.

For convenience dissolved undissociated carbon dioxide is often written as $\mathrm{H}_{2} \mathrm{CO}_{3}$. Actually, only a small part of the dissolved carbon dioxide is hydrated. However, published dissociation constants for carbonic acid are actually to be applied to total dissolved carbon dioxide unless the value is specifically stated to apply only to the hydrated part. For the dissociations

$$
\mathrm{H}_{2} \mathrm{CO}_{3} \rightleftharpoons \mathrm{HCO}_{3}{ }^{-}+\mathrm{H}^{+}
$$

and

$$
\mathrm{HCO}_{3}{ }^{-} \rightleftharpoons \mathrm{CO}_{3}{ }^{-2}+\mathrm{H}^{+}
$$

the values for equilibrium constants $K_{1}$ and $K_{2}$, given by Latimer $(1952$, p. 135$)$ are $4.16 \times 10^{-7}$ and $4.84 \times 10^{-11}$, respectively. Therefore

$$
\frac{\left[\mathrm{HCO}_{3}^{-}\right]\left[\mathrm{H}^{+}\right]}{\left[\mathrm{H}_{2} \mathrm{CO}_{3}\right]}=4.16 \times 10^{-7}
$$

and

$$
\frac{\left[\mathrm{CO}_{3}^{-2}\right]\left[\mathrm{H}^{+}\right]}{\left[\mathrm{HCO}_{3}^{-}\right]}=4.84 \times 10^{-11}
$$

In the second equilibrium, where the $\mathrm{pH}$ is less than about 8.3 , the value of the ratio $\left[\mathrm{CO}_{3}\right]:\left[\mathrm{HCO}_{3}\right]$ is less than 0.01 . Consequently, below $\mathrm{pH} 8.3$, the amount of depletion of the dissolved carbon dioxide 
resulting from the second dissociation is a relatively minor factor. For the water analyses in table 1 , the equation

$$
\left[\mathrm{H}_{2} \mathrm{CO}_{3}\right]=\frac{\left[\mathrm{HCO}_{3}^{-}\right]\left[\mathrm{H}^{+}\right]}{K_{1}}
$$

will yield satisfactory values for dissolved undissociated carbon dioxide. Two sets of computed values for dissolved undissociated carbon dioxide are given in table 2 . One set was obtained by substituting measured concentrations of $\mathrm{HCO}_{3}{ }^{-}$from the analysis in the equation. The other set was obtained by using determined $\mathrm{HCO}_{3}^{-}$ and a computed activity coefficient. In computing the second value for dissolved carbon dioxide, the activity coeficient enters the numerator of the right-hand side of the equation, and results in a lower computed value for dissolved undissociated carbon dioxide. The maximum correction amounts to 25 percent at ionic strength 0.11 , and is relatively minor for the more dilute water samples of table 1 . The computed carbon dioxide value is the activity of dissolved undissociated carbon dioxide in the solution; but for undissociated species, an activity coefficient of unity can be assumed here. Hence, the computed value can be taken as the molal concentration.

If the $\mathrm{pH}$ of the solution is above about 8.3 , the second dissociation must also be considered in computing the activity of undissociated dissolved carbon dioxide.

Calculation of the amount of undissociated dissolved carbon dioxide in laboratory samples is readily possible when the temperature is near $25^{\circ} \mathrm{C}$, and $\mathrm{pH}$ and bicarbonate ion concentration are measured at the same time, provided enough information is available to calculate ionic strength. Application of laboratory data to field conditions, however, may not be valid because of changes that can occur in the chemical system during transfer from field to laboratory.

\section{SOLUTION AND DEPOSITION OF CALCITE}

Another computation of great interest in natural-water chemistry relates to the equilibrium between carbonate minerals in contact with water containing $\mathrm{H}^{+}$, and the dissociated ions in solution that result. A water analysis provides information relating to the equilibrium

$$
\mathrm{CaCO}_{3}+\mathrm{H}^{+} \rightleftharpoons \mathrm{HCO}_{3}{ }^{-}+\mathrm{Ca}^{+2}
$$

Langelier (1936) suggested a computation for evaluating the stability of water that had been softened in water-treatment plants that used this equilibrium. The equilibrium is also of interest in studies of the chemistry of natural water which may be associated with carbonate minerals. From free-energy data, a value of $0.97 \times 10^{2}$ is 


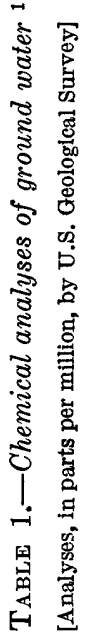

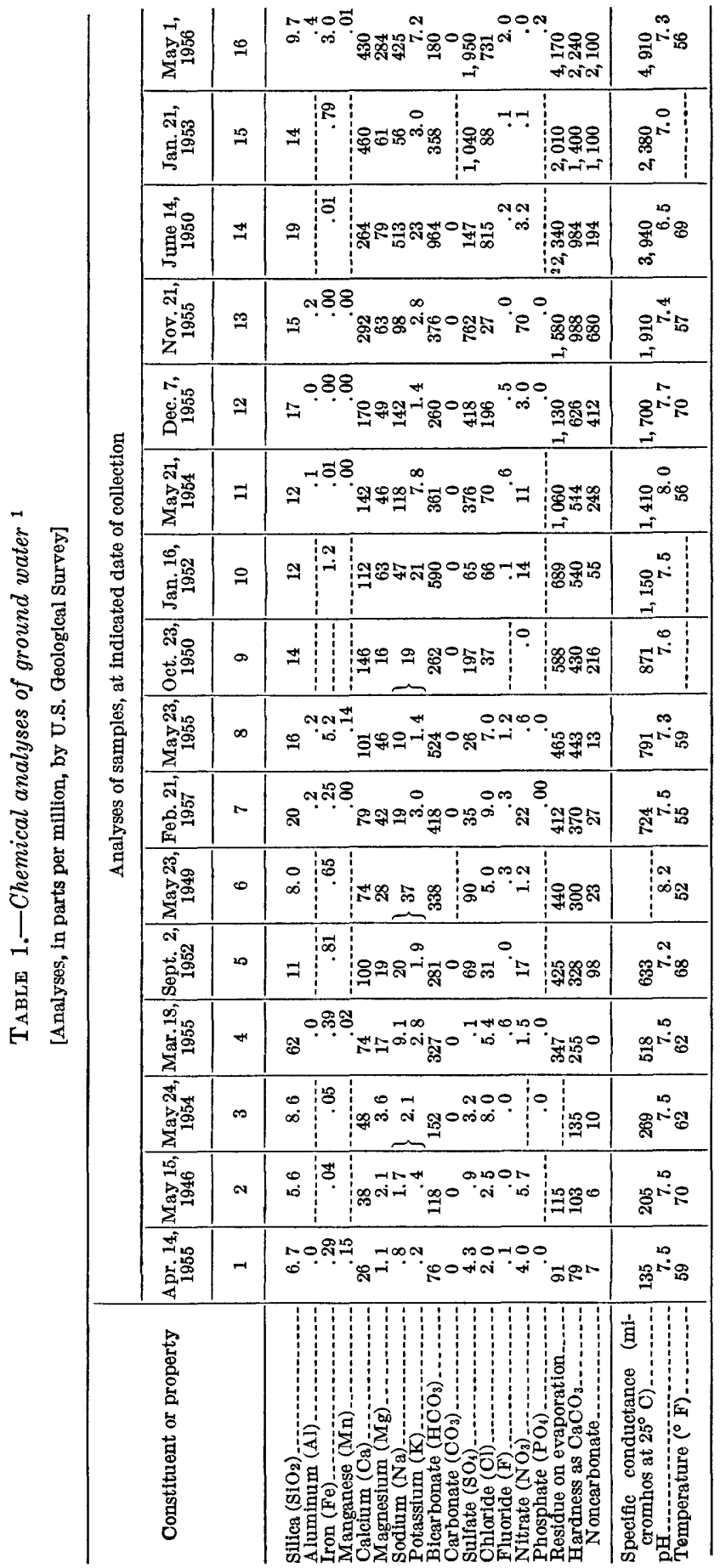



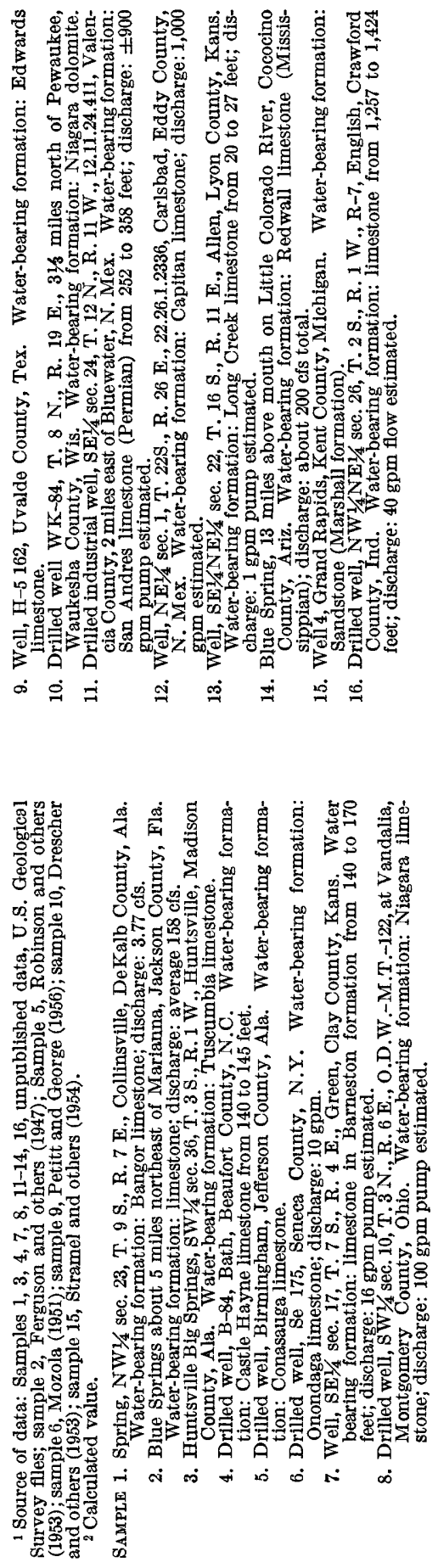
TABLE 2.-Computation of undissociated carbon dioxide

\begin{tabular}{|c|c|c|c|c|c|c|c|c|}
\hline \multirow{2}{*}{ Sample } & \multirow{2}{*}{ 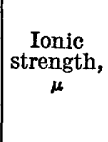 } & \multicolumn{4}{|c|}{$\mathrm{HCO}_{3}$} & \multicolumn{2}{|c|}{$\mathrm{CO}_{2}(\mathrm{ppm})$} & \multirow{2}{*}{ pH } \\
\hline & & $\begin{array}{l}\text { Equiva- } \\
\text { lents per } \\
\text { million }\end{array}$ & $\begin{array}{l}\text { (Moles per } \\
\text { liter) }\end{array}$ & $\begin{array}{c}\text { Activity } \\
\text { coeffi- } \\
\text { cient, } \gamma\end{array}$ & $\begin{array}{c}\text { Activity } \\
\text { (moles per } \\
\text { liter) }\end{array}$ & $\begin{array}{l}\text { From } \\
\text { concen- } \\
\text { tration }\end{array}$ & $\underset{\text { activity }}{\text { From }}$ & \\
\hline $\begin{array}{l}1 \\
2 \\
3\end{array}$ & $\begin{array}{l}0.0022 \\
.0030 \\
.0040 \\
.0078 \\
.011 \\
.011 \\
.012 \\
.014 \\
.016 \\
.019 \\
.025 \\
.029 \\
.040 \\
.052 \\
.052 \\
.011\end{array}$ & $\begin{array}{r}1.246 \\
1.934 \\
2.491 \\
5.36 \\
4.61 \\
5.54 \\
6.85 \\
8.59 \\
4.29 \\
9.67 \\
5.92 \\
4.26 \\
6.16 \\
15.80 \\
5.87 \\
2.95\end{array}$ & $\begin{array}{l}\text { 1. } 2 \times 10^{-3} \\
\text { 1. } 9 \times 10^{-3} \\
2.5 \times 10^{-3} \\
5.4 \times 10^{-3} \\
4.6 \times 10^{-3} \\
\text { 5. } 5 \times 10^{-3} \\
6.8 \times 10^{-3} \\
8.6 \times 10^{-3} \\
4.3 \times 10^{-3} \\
9.7 \times 10^{-3} \\
5.9 \times 10^{-3} \\
4.3 \times 10^{-3} \\
6.2 \times 10^{-3} \\
1.6 \times 10^{-2} \\
\text { 5. } 9 \times 10^{-3} \\
\text { 3. } 0 \times 10^{-3}\end{array}$ & $\begin{array}{l}0.69 \\
.95 \\
.94 \\
.92 \\
.90 \\
.90 \\
.89 \\
.88 \\
.87 \\
.87 \\
.86 \\
.85 \\
.84 \\
.82 \\
.82 \\
.77\end{array}$ & $\begin{array}{l}\text { 1. } 2 \times 10^{-3} \\
1.8 \times 10^{-3} \\
2.4 \times 10^{-3} \\
\text { 5. } 0 \times 10^{-3} \\
\text { 4. } 1 \times 10^{-3} \\
\text { 5. } 0 \times 10^{-3} \\
\text { 6. } 0 \times 10^{-3} \\
\text { 7. } 6 \times 10^{-3} \\
\text { 3. } 7 \times 10^{-3} \\
8.4 \times 10^{-3} \\
\text { 5. } 1 \times 10^{-3} \\
3.7 \times 10^{-3} \\
\text { 5. } 2 \times 10^{-3} \\
1.3 \times 10^{-2} \\
4.8 \times 10^{-3} \\
2.3 \times 10^{-3}\end{array}$ & $\begin{array}{c}4.2 \\
6.6 \\
8.5 \\
18 \\
31 \\
3.7 \\
23 \\
46 \\
11 \\
33 \\
6.3 \\
9.0 \\
26 \\
536 \\
62 \\
16\end{array}$ & $\begin{array}{c}4.0 \\
6.3 \\
7.9 \\
17 \\
28 \\
3.3 \\
21 \\
40 \\
9.9 \\
29 \\
5.4 \\
7.7 \\
22 \\
440 \\
51 \\
12\end{array}$ & $\begin{array}{l}7.5 \\
7.5 \\
7.5 \\
7.5 \\
7.2 \\
8.2 \\
7.5 \\
7.3 \\
7.6 \\
7.5 \\
8.0 \\
7.7 \\
7.4 \\
6.5 \\
7.0 \\
7.3\end{array}$ \\
\hline
\end{tabular}

obtained for $K_{e q}$ for the calcite equilibrium. Aragonite is somewhat more soluble, and the equilibrium constant for the equilibrium involving this mineral is $1.48 \times 10^{2}$. At normal temperature and pressure in ground-water environments, aragonite would therefore be preferentially dissolved if the water were saturated with respect to calcite and calcite would be preferentially precipitated if the water became saturated with respect to aragonite. Accordingly, calcite is likely to be much more common in aquifers than aragonite.

If calcite is present in an aquifer, and if the calcite is relatively pure, unit activity may be assigned to the mineral and the following relation assumed

$$
-\log \frac{\left[\mathrm{Ca}^{+2}\right]\left[\mathrm{HCO}_{3}^{-}\right]}{K_{e q}}=\mathrm{pH} \text { (calculated) }
$$

If the ground water is in equilibrium with calcite, the calculated $\mathrm{pH}$ value should closely agree with the actual value in the water.

For conducting an equilibrium experiment in the laboratory under controlled conditions, methods could be devised to determine $\mathrm{pH}$ and calcium and bicarbonate contents of solutions with assurance that the measurements represented actual conditions in the system. Obtaining measurements of equal dependability on ground water in its native state, however, is a more difficult problem. The calcium and bicarbonate contents of most ground water are relatively stable, and samples of the water taken and handled with ordinary care will give values on analysis that can be safely assumed to represent the composition of water in the aquifer. The same cannot always be said for the 
measured $\mathrm{pH}$. When the $\mathrm{pH}$ measurement is made carefully in the field at the time samples are obtained, it should represent reasonably well the $\mathrm{pH}$ of the water in the aquifer. When the $\mathrm{pH}$ measurement is made on the sample several days or weeks after collection, however, the value obtained may differ from that of the water in its natural surroundings.

The hydrogen-ion activity of most natural water is a small quantity in comparison with the dissolved constituents determined in the normal water analysis. At $\mathrm{pH} 7$, for example, the hydrogen-ion activity is equivalent to only $0.0001 \mathrm{ppm} \mathrm{H}^{+}$. The degree to which this quantity can be held constant until a measurement can be made is uncertain. In some water, the $\mathrm{pH}$ is stable, in other water it is unstable. During research by the Geological Survey from 1955 to 1957 , a large number of field $\mathrm{pH}$ determinations were made by experienced personnel with accurate equipment. Laboratory $\mathrm{pH}$ measurements were made later on the samples collected at the same time as the field measurements were made.

A comparison of 165 sets of field and laboratory $\mathrm{pH}$ data shows that the average difference is about $\pm 0.3 \mathrm{pH}$ unit. Some of the water was unstable, and field and laboratory $\mathrm{pH}$ values for these samples differed by $1.0 \mathrm{pH}$ unit or more. However, the unstable water was from geologic sources in which calcium carbonate was in very short supply; hence, the water did not resemble samples whose analyses are given in this report.

Analyses in table 1 represent water having a wide range of dissolvedsolids concentration and the samples come from many different geologic sources in the United States. With one exception, however, the samples all come from limestone or dolomite. In table 3, computed $\mathrm{pH}$ values for the water are compared with the values determined in the laboratory. One computed $\mathrm{pH}$ value was prepared by using the reported $\mathrm{Ca}^{+2}$ and $\mathrm{HCO}_{3}$ - concentrations from the analysis; another computed value was obtained by using concentrations corrected by activity coefficients.

The activity coefficient, $\gamma$, increases the computed $\mathrm{pH}$ by the amount

$$
\Delta \mathrm{pH}=-\log \gamma_{\mathrm{Ca}^{+2}} \gamma_{\mathrm{HCO}_{3}}{ }^{-}
$$

In the examples shown in table $3, \Delta \mathrm{pH}$ is from 0.1 to as much as 0.6 unit. The $\mathrm{pH}$ computed with the aid of activity coefficients comes nearer agreement with the observed $\mathrm{pH}$ than the uncorrected computed value in every sample except the 3 most dilute: sample 1 had a low bicarbonate content, and possibly an unstable $\mathrm{pH}$; and agreement of all 3 values was close for samples 2 and 3 . 


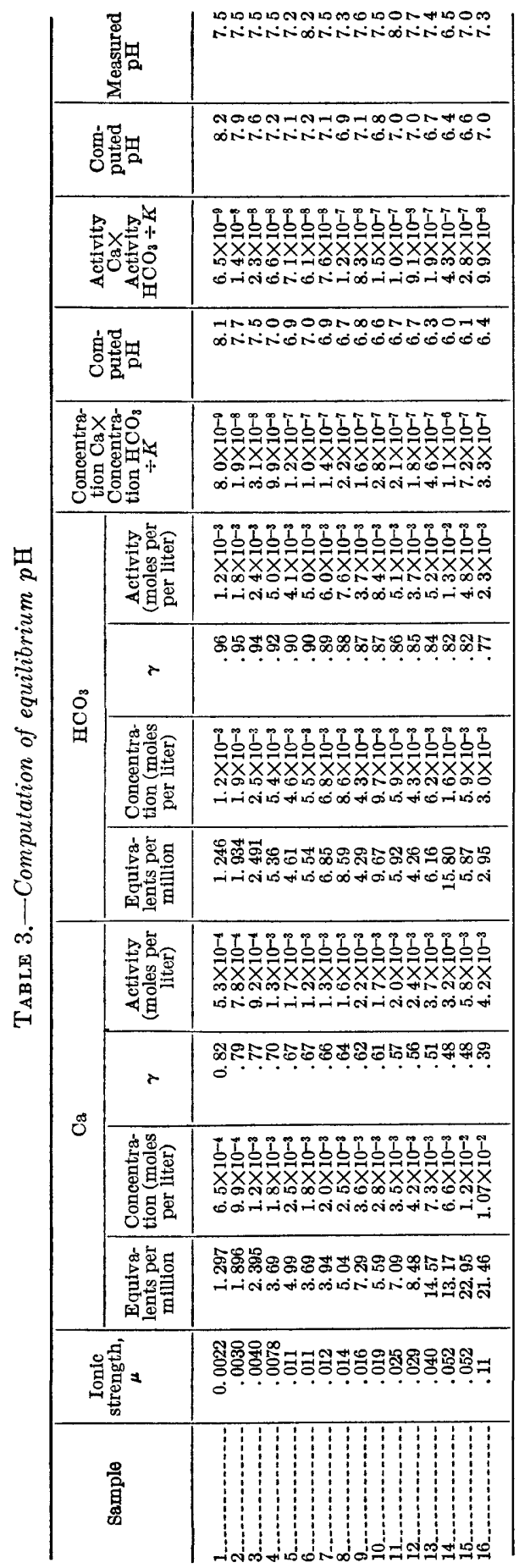


Differences between measured $\mathrm{pH}$ and computed $\mathrm{pH}$ on the order of $0.3 \mathrm{pH}$ unit could be expected to result solely from possible changes in $\mathrm{pH}$ during the transfer from field to laboratory. Larger differences from the same cause could sometimes occur; accordingly, for data of the kind given in tables 1 and 3, differences between measured and computed $\mathrm{pH}$ should be interpreted with caution.

Although the activity coefficient correction may sometimes be minor compared to the uncertainty introduced by assumptions regarding the effects of possible environmental variables, the activity coefficients eliminate questions as to possible error that is introduced when their value is assumed to be unity.

The data in table 3 show how the water samples would react at the time of analysis if they were brought in contact with calcite of the composition $\mathrm{CaCO}_{3}$. If the data are assumed to be representative of conditions in the aquifer (this may not always be a safe assumption) some interesting speculations about the relation between the chemical constituents in the aquifer are possible. Calcite very probably is present in the aquifers represented in table 1; but this also has been assumed without positive proof. In studies where the chemical analyses of water were planned to be used for computation of equilibrium status with respect to calcite, field $\mathrm{pH}$ data should be obtained and samples of aquifer material should be examined for calcite.

Because of possible uncertainties in the $\mathrm{pH}$ measurements used in this discussion, equilibrium is assumed to exist when the measured and computed $\mathrm{pH}$ values agree to \pm 0.5 unit. With better data, this range could probably be decreased. Analysis 1 seems to represent undersaturation, and analyses 6 and 10-13 are supersaturated with respect to calcite. The activity coefficient correction brings computed $\mathrm{pH}$ values for analyses 7-9, and 15-16 into close agreement with the measured value. Uncorrected $\mathrm{pH}$ values for these five samples also would have indicated supersaturation.

Analysis 1 represents water from a humid region and an aquifer where water probaby circulates rapidly. In such a system, the ground water could be discharged so rapidly that there would not be time for equilibrium with respect to calcite to be reached.

Analyses that seem to show a great degree of supersaturation with respect to calcite could precipitate calcium carbonate from solution, a significant fact in hydrology and geology. The water of analysis 6 has an equilibrium $\mathrm{pH}$ a full unit below the observed value. To reach equilibrium, about half the calcium and an equivalent \&mount of bicarbonate would have to precipitate as calcite. From 1,000 gallons of this water, nearly 1 pound of calcium carbonate precipitate would be obtained. A sudden change in pressure head or other alteration in the environment of the water could cause at least some calcium 
carbonate to precipitate. When water moves into the area of influence of a punping well, a marked pressure differential can take place, and this could explain calcium carbonate deposits on well screens or in the water-bearing material outside the well bore. Such deposits may seriously interfere with the production of water. Possibly, such deposits also form when unstable water is left standing in the well bore after the pump is shut down.

Changes in $\mathrm{pH}$ as calcium bicarbonate water saturated with respect to calcite moves into a noncalcareous rock formation can explain the commonly observed cementing of sandstones with calcite.

If the solutes in water are in equilibrium with a solid phase that is not pure calcite, the assumptions made in computing the equilibrium $\mathrm{pH}$ are not entirely valid. If the solid phase is dolomite, as in analysis 10 , an equilibrium constant applicable to dolomite or a dolomite-calcite mixture should be used. Values for $K$ for such an equilibrium, however, are not readily available.

The apparent metastability of surface water that was supersaturated with respect to calcite has been noted in the literature of limnology. Ohle (1952) and other authors have attributed this to a colloidal or undissociated form of calcium carbonate in solution. The threshold effect of small amounts of polyphosphates in water treatment can also make solutions metastable. The threshold effect is generally attributed to surface activity of the added polyphosphate which prevents the calcium carbonate particles from growing large enough to form a precipitate.

Alekin and Moricheva (1957) have discussed apparent supersaturation of the water of major rivers of Russia and attribute the apparent stability of the water for periods as long as 30 days to threshold effects exerted by organic matter.

Calcium carbonate tends to precipitate from the water in some reservoirs. The effect is particularly marked in Lake Mead, in which water of the Colorado River is held in storage. The capacity of the reservoir is so large that the average residence time of the water may be several years. Evidently, the precipitation of calcium carbonate can be slow under some circumstances. Evidence for calcium carbonate (aqueous phase) or for threshold effects being involved in not conclusive.

Figure 2 may be used to estimate equilibrium values for the $\mathrm{pH}$ of natural water that is in contact with calcite. To use the diagram, ionic strength of the water and activity coefficients for calcium and bicarbonate ions should be computed first, by using plate 1 and figure 1. The activity coefficients then should be applied to the reported concentrations of calcium and bicarbonate in the water analyses to give activities of these ions. 


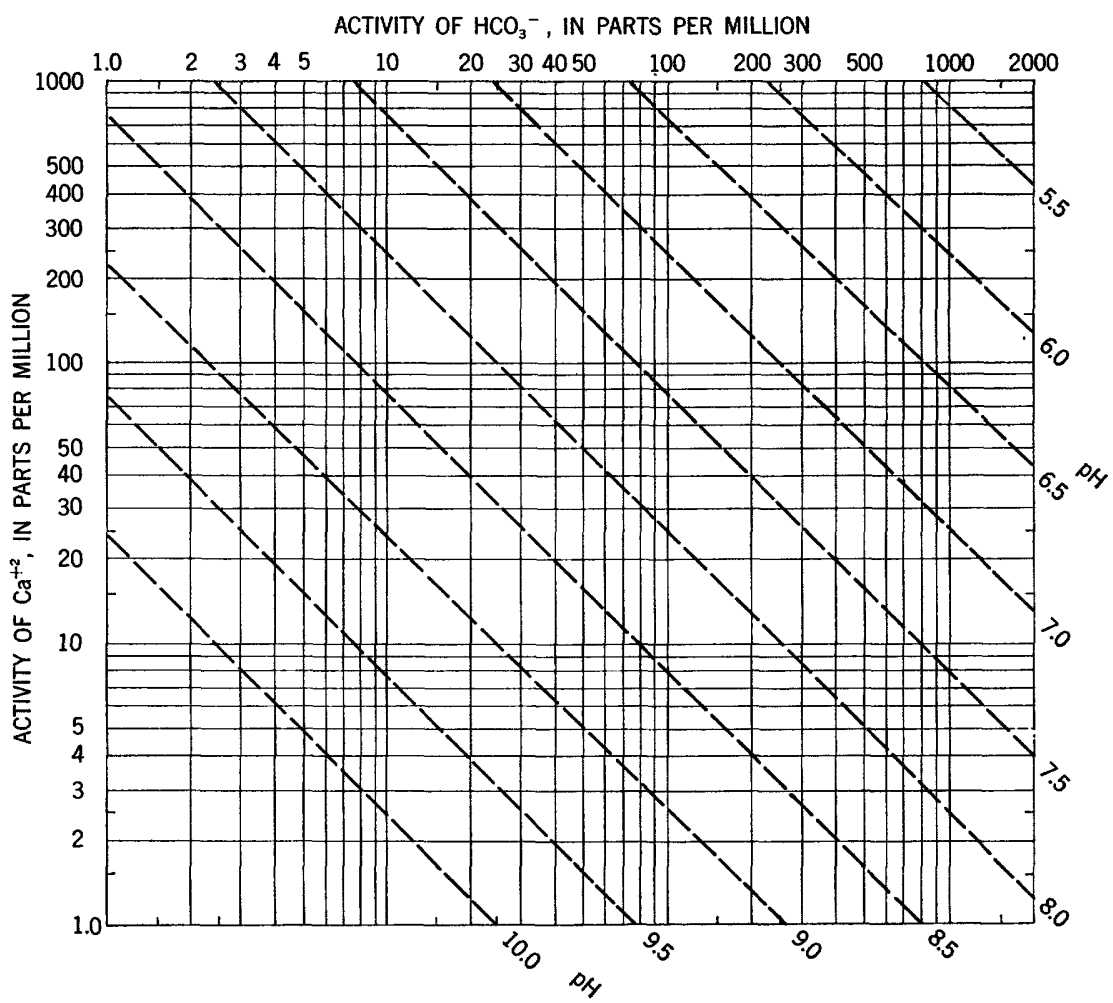

Figure 2.-Equilibrium pH for calcium and bicarbonate activities from 1.0 to $2,000 \mathrm{ppm}$ in solutions in contact with calcite. Pressure $=1$ atmosphere; temperature $=25^{\circ} \mathrm{C}$.

The foregoing discussion has outlined a method for determining whether water in a given environment is undersaturated or supersaturated with respect to calcite. Two kinds of information, which have not generally been obtained in water-resources investigations, are required to utilize the method satisfactorily. If (a) accurate field $\mathrm{pH}$ data are obtained, and (b) mineralogic studies of the minerals associated with the water show that calcite reasonably close to $\mathrm{CaCo}_{3}$ in composition is present, then the saturation computation can be applied geologically and hydrologically. For example, the degree of saturation should be lowest in recharge areas, and should increase as water movers through the aquifer.

\section{REDOX EQUILIBRIA}

Another type of chemical equilibrium in natural water is that involving oxidation and reduction. Theoretical evaluations of such equilibria are based on the Nernst equation. The author has used this treatment in discussions of the chemistry of iron in natural water 
(Hem and Cropper, 1959; Hem, 1960), and details are not repeated here.

In computing the redox potential (Eh) of ground water from the $\mathrm{pH}$ and iron content, the Nernst equation takes the form,

$$
\mathrm{Eh}=E^{0}+0.059 \log \frac{\left[\mathrm{Fe}^{+3} \text { species }\right]}{\left[\mathrm{Fe}^{+2} \text { species }\right]}
$$

where $E^{0}$ is the standard potential of the couple considered.

The value for activity of ferric species is obtained from the $\mathrm{pH}$ by computation, and no correction by activity coefficient is involved in this term. The ferrous concentration, however, is subject to correction because it is obtained from the water analysis results. The activity coefficients for ferrous iron are the same as those for calcium (fig. 1). The Nernst equation tends to minimize the effect of activity corrections, however. In calculating the Eh value based on the ferricferrous equilibrium, the correction amounts to only +0.02 volt for the sample in table 1 containing the largest amount of dissolved solids. Accordingly, it seems that activity corrections are comparatively small in calculations of Eh from iron content and $\mathrm{pH}$ according to techniques suggested by Hem (1960). Some uncertainty in the calculation of the Eh of natural water may be introducted by ignoring possible carbonate or bicarbonate complexes, but no data on such complexes are presently available.

In redox equilibria involving other than ferrous and ferric ions, the effects of the activity correction would be different. The correction to Eh resulting from the use of activity coefficients $(\Delta \mathrm{Eh})$ will be

$$
\Delta \mathrm{Eh}=\frac{0.059}{n} \log \frac{\gamma_{\text {oxldation }}}{\gamma_{\text {reduction }}}
$$

where $n$ is number of electrons involved in the oxidation.

If $n$ is greater than 1 , the effect of the activity correction becomes less important. If $\gamma_{\text {oxidation }}$ is greatly different from $\gamma_{\text {roduction }}$ the value of $\Delta \mathrm{Eh}$ will be greater. The maximum value $\Delta \mathrm{Eh}$ could attain in soluutions up to 0.10 ionic strength, however, is not much over 0.03 volt, because when $\gamma_{\text {oxidation }}$ differs greatly from $\gamma_{\text {reduction }}$ the value of $n$ will generally be much greater than 1 . 


\section{LITERATURE CITED}

Alekin, O. A., and Moricheva, N. P., 1957, The problem of the stability of the carbonate system in natural water: Doklady Akad. Nauk. SSSR [Geochem. Sec.], v. 117, p. 1030.

Drescher, W. J., Dreher, F. C., and Brown, P. N., 1953, Water resources of the Milwaukee area, Wisconsin: U.S. Geol. Survey Circ. 247, p. 32.

Ferguson, G. E., Lingham, C. W., Love, S. K., and Vernon, R. O., 1947, Springs of Florida-Blue Springs: Dept. Conserv., Florida Geol. Survey, Bull. no. 31, p. 87.

Hem, J. D., 1960, Restraints on ferrous iron imposed by bicarbonate, redox potential, and pH: U.S. Geol. Survey Water-Supply Paper 1459-B, p. 33-56.

Hem, J. D., and Cropper, W. H., 1959, Survey of ferrous-ferric chemical equilibria and redox potentials: U.S. Geol. Survey Water-Supply Paper 1459-A p. 1-31.

Langelier, W. F., 1936, The analytical control of anticorrosion water treatment: Am. Water Works Assoc. Jour., v. 28, p. 1500-1521.

Latimer, W. M., 1952, Oxidation potentials: New York, Prentice-Hall, 392 p.

Klotz, I. M., 1950, Chemical thermodynamics: New York, Prentice-Hall, p. $329-332$.

Moore, E. W., 1939, Graphic determination of carbon dioxide and the three forms of alkalinity: Am. Water Works Assoc. Jour., v. 31, p. 51-66.

Mozola, A. J., 1951, The ground water resources of Seneca County, New York: New York Dept. Conserv., Water Power and Control Comm., p. 31.

Ohle, W., 1952, Die hypolimnische Kohlendioxyde-Akkumulation als productions biologischer indikator: Arch. Hydrobiol., v. 46, p. 153-285.

Petitt, B. M., Jr., and George, W. O., 1956, Ground water resources of the San Antonio area, Texas: Texas Board Water Engineers, Bull. 5608, v. 2, pt. 3, p. IV-6.

Robinson, W. H., Ivey, J. B., and Billingsley, G. A., 1953, Water supply of the Birmingham area, Alabama: U.S. Geol. Survey Cire. 254, p. 47.

Stramel, G. J., Wisler, C. O., and Laird, L. B., 1954, Water resources of the Grand Rapids area, Michigan: U.S. Geol. Survey Circ. 323, p. 26. 


